University of Wollongong

Research Online

Faculty of Engineering and Information

Faculty of Engineering and Information

Sciences - Papers: Part A

Sciences

$1-1-2012$

Performance of a reinforced embankment on a sensitive Champlain clay deposit

Chalermpol Taechakumthorn

University of Wollongong, ctaechak@uow.edu.au

R K. Rowe

Queen's University - Kingston, Ontario

Follow this and additional works at: https://ro.uow.edu.au/eispapers

Part of the Engineering Commons, and the Science and Technology Studies Commons

Research Online is the open access institutional repository for the University of Wollongong. For further information contact the UOW Library: research-pubs@uow.edu.au 


\title{
Performance of a reinforced embankment on a sensitive Champlain clay deposit
}

\begin{abstract}
An existing elastoviscoplastic constitutive model is modified using concepts of the state-dependent fluidity parameters and the damage law, to incorporate the effect of soil structure and its destructuration. The model is employed to simulate the performance of a well-documented case study of the reinforced test embankment constructed over a sensitive Champlain clay deposit at Saint Alban, Quebec. The finite element calculations, using both the original (nonstructured) and modified (structured) elastoviscoplastic soil models, are compared with the observed field data from a test embankment brought to failure. The results from the structured elastoviscoplastic soil model show better agreements with the field data when compared with those analyzed using the nonstructured elastoviscoplastic soil model. The modified model captures many features of the reinforced embankment behaviour, such as vertical settlement, excess pore-water pressure responses, and reinforcement force. However, they also reveal the fact that another important characteristic of the natural clay deposit - anisotropy - needs to be considered to provide an adequate prediction of horizontal deformations. The role of geosynthetic reinforcement and its viscosity on short-term responses of the reinforced embankment examined in this study is also discussed
\end{abstract}

\section{Keywords}

sensitive, clay, embankment, reinforced, performance, champlain, deposit

Disciplines

Engineering | Science and Technology Studies

\section{Publication Details}

Taechakumthorn, C. \& Rowe, R. K. (2012). Performance of a reinforced embankment on a sensitive Champlain clay deposit. Canadian Geotechnical Journal, 49 (8), 917-927. 
Performance of a reinforced embankment on a sensitive Champlain clay deposit

Chalermpol Taechakumthorn

Former PhD student, GeoEngineering Centre at Queen's-RMC, Department of Civil Engineering, Queen's University, Canada

\section{R. Kerry Rowe*}

Professor and Canada Research Chair in Geotechnical and Geoenvironmental Engineering, GeoEngineering Centre at Queen's-RMC, Department of Civil Engineering, Queen's University, Kingston, ON, Canada K7L 3N6, Telephone: +1 613533 3113, Telefax: +1 613533 2128, Email: kerry@civil.queensu.ca

\footnotetext{
* Corresponding author
}

Published as:

Taechakumthorn, C. and Rowe, R.K. (2012) "Performance of a reinforced embankment on a sensitive Champlain clay deposit", Canadian Geotechnical Journal, 49(8): 917-927. 


\section{Notation}

\begin{tabular}{|c|c|}
\hline$\varnothing^{\prime}$ & friction angle \\
\hline$\psi$ & dilation angle \\
\hline$\dot{\varepsilon}_{i j}$ & strain rate tensor \\
\hline$\dot{\varepsilon}_{a}$ & axial strain rate \\
\hline$\dot{\varepsilon}_{n v}$ & threshold strain rate \\
\hline$S_{i j}$ & deviatoric stress \\
\hline E & Young's modulus \\
\hline$G$ & shear modulus \\
\hline$\sigma_{i i}$ & summation of the principal stresses \\
\hline$K$ & bulk modulus \\
\hline$v$ & Poisson's ratio \\
\hline$e_{o}$ & initial void ratio \\
\hline$k_{o}$ & initial hydraulic conductivity \\
\hline$C_{k}$ & hydraulic conductivity change index \\
\hline$P_{a}$ & atmospheric pressure \\
\hline$\varnothing(F)$ & flow function \\
\hline$\sigma_{o s}^{\prime(d)}$ & overstress \\
\hline$n$ & strain rate exponent \\
\hline$f$ & plastic potential function and yield surface \\
\hline$l$ & mean effective stress corresponding to the center of the ellipse \\
\hline$R$ & the ratio between major and minor axis of the ellipse \\
\hline$\sigma_{m}^{\prime}$ & mean effective stress \\
\hline$\sigma_{m y}^{\prime}$ & intercept of the ellipse with the $\sigma_{m}^{\prime}$ axis \\
\hline$\sigma_{p}^{\prime}$ & preconsolidation pressure \\
\hline$M_{N / C}$ & slope of the failure surface in normally consolidated soil \\
\hline$M_{O / C}$ & slope of the failure surface in overconsolidated soil \\
\hline$\lambda$ & critical parameter - compression index \\
\hline
\end{tabular}




\section{Notation (continued)}

$\begin{array}{ll}\kappa & \text { critical parameter - recompression index } \\ J & \text { reinforcement axial tensile stiffness } \\ \gamma_{s}^{v p} & \text { fluidity of the undisturbed clay fabric } \\ \gamma_{i}^{v p} & \text { fluidity of the destructed clay fabric } \\ \gamma^{v p}\left(\varepsilon_{d}\right) & \text { state-dependent fluidity of the clay fabric } \\ \omega_{o} & \text { parameter define soil structure level } \\ \omega\left(\varepsilon_{d}\right) & \text { state-dependent soil structure level } \\ \varepsilon_{d} & \text { damage strain } \\ d \varepsilon_{d} & \text { incremental damage strain } \\ d \varepsilon_{v o l}^{v p} & \text { incremental plastic volumetric strain } \\ d \varepsilon_{s}^{v p} & \text { incremental plastic shear strain } \\ \alpha & \text { material parameter governing the rate of destructuration } \\ A & \text { weighting parameter } \\ K_{s} \text { and } m & \text { material constants for nonlinear elastoplastic fill material } \\ \sigma_{T} & \text { tensile stress of the independent spring } \\ a_{o}, a_{1}, \delta, \beta & \text { material constants for nonlinear viscoelastic reinforcement } \\ n_{K} & \text { number of Kelvin elements } \\ \tau_{i} & \text { retardation time } \\ E_{i} & \text { dashpot viscosity } \\ \eta_{i} & \end{array}$




\title{
Performance of a reinforced embankment on a sensitive Champlain clay deposit
}

\author{
C. Taechakumthorn ${ }^{1}$ and R. Kerry Rowe ${ }^{2}$ \\ GeoEngineering Centre at Queen's-RMC \\ Department of Civil Engineering, Queen's University, Canada
}

\begin{abstract}
An existing elasto-viscoplastic constitutive model is modified using concepts of the statedependent fluidity parameters and the damage law, to incorporate the effect of soil structure and its destructuration. The model is employed to simulate the performance of a well documented case study of the reinforced test embankment constructed over sensitive Champlain clay deposit at Saint Alban, Quebec. The finite element calculations, using both original (non-structured) and modified (structured) elasto-viscoplastic soil model, are compared with the observed field data from a test embankment brought to failure. The results from the structured elasto-viscoplastic soil model show better agreement with the field data than those obtained using a non-structured elasto-viscoplastic soil model. The modified model captures many features of the reinforced embankments observed behaviour such as vertical settlement, excess pore water pressure response and reinforcement force. However, the horizontal deformations in the clay deposit were not modeled satisfactorily. The role of geosynthetic reinforcement and its viscosity on the shortterm response of the reinforced embankment is also discussed
\end{abstract}

KEYWORDS: elasto-viscoplastic; strain softening; embankment; reinforced soil; numerical modelling; time-dependent behaviour, rate-sensitive clay.

\footnotetext{
${ }^{1}$ Former PhD student, GeoEngineering Centre at Queen's-RMC, Department of Civil Engineering, Queen's University, Canada

${ }^{2}$ Professor of Civil Engineering, GeoEngineering Centre at Queen's-RMC, Department of Civil Engineering, Queen's University, Canada, 613-533-3113, Fax 613-533-2128: Corresponding author, e-mail:

kerry@civil.queensu.ca
} 


\section{Introduction}

2 In many parts of eastern Canada and Scandinavia, soft clay deposits are highly sensitive. For

3 these sensitive/structured soils, deformation and plastic strain will break down inter-particle

4 bonding and results in a post peak strength reduction which may significantly affect the

5 behaviour of soft clay deposits (Vaid et al. 1979; Quigley 1980; Leroueil and Vaughan 1990;

6 Burland 1990; Torrance 1999; Malandraki and Toll 2000; Lo and Hinchberger 2006; and

7 Hinchberger and Qu 2009). A number of constitutive models have been proposed for structured

8 and rate-sensitive clays (e.g., Kim and Leroueil 2001; Rocchi et al. 2003; and Hinchberger and

9 Qu 2009).

Rowe and Hinchberger (1998) proposed an elasto-viscoplastic constitutive model based

11 on the concept of over stress viscoplasticity (Perzyna 1963). The model has been extensively

12 verified and provides good prediction for the behaviour of field test embankments constructed on

13 non-structured and rate-sensitive foundation soils (Hinchberger 1996; Hinchberger and Rowe

14 1998; and Rowe and Hinchberger 1998). Hinchberger and Qu (2009) extended the Rowe and 15 Hinchberger (1998) model using the concept of state-dependent fluidity parameters and a 16 damage law to describe the destructuration of rate-sensitive structured clay. Hinchberger and Qu 17 (2009) also demonstrated that the proposed model can adequately describe many features of soil 18 behaviour such as accelerated creep rupture, post-peak strength reduction as well as the strain 19 rate dependency of the undrained shear strength and the apparent preconsolidation pressure of 20 the Saint Jean Vianney clay in the laboratory. Despite good predictions of the laboratory results, 21 the model has never been tested against the full scale test data.

In this study, the Hinchberger and Qu (2009) structured elasto-viscoplastic soil model is

23 implemented into the finite element program; AFENA (Carter and Balaam 1990) for two- 
dimensional (2D) plane strain analysis. The model is used to simulate the performance of a well documented case study of the reinforced test embankment constructed on sensitive Champlain clay deposit in Saint Alban, Quebec (Busbridge et al. 1985). The calculated results are compared with the observed field data and those predicted using the non-structured elasto-viscoplastic soil model [i.e. Rowe and Hinchberger (1998)]. The structured elasto-viscoplastic soil model is then employed to investigate the effect of reinforcement and its viscosity on the short-term behaviour of the reinforced embankment examined in this study. The practical implications as well as the effectiveness and limitations of the model are also discussed. .

\section{Ground condition at Saint Alban}

The subsurface conditions across the site area where the embankment under consideration was constructed are inferred from a detailed geotechnical investigation reported by Trak et al. (1980), Leroueil et al. (1983), Tavenas et al. (1983), Lefebvre et al. (1988) and Lefebvre and Pfendler (1996). The soil profile consists of a $2.0 \mathrm{~m}$ thick weathered clay crust underlain by a $13.7 \mathrm{~m}$ thick deposit of soft grey blue marine clay. Beneath the clay there is a layer of dense fine to medium coarse sand underlain by bedrock. The groundwater table is at $0.7 \mathrm{~m}$ below the ground surface. Studies of this soft clay indicated that the deposit has low to medium plasticity, with measured water contents appreciably higher than the liquid limit. The clay in the crust is lightly overconsolidaed, with an overconsolidation ratio (OCR) of about 2.2. The bulk unit weight of the soil in the crust is estimated to be $19 \mathrm{kN} / \mathrm{m}^{3}$, whereas that of the soil below the crust is $16 \mathrm{kN} / \mathrm{m}^{3}$. Figure 1 presents a typical profile of the geotechnical properties of the soft deposit - modified from Trak et al. (1980). 
The permeability (hydraulic conductivity) of Champlain clays ranges between $10^{-10} \mathrm{~m} / \mathrm{s}$ and $10^{-8} \mathrm{~m} / \mathrm{s}$ depending on the void ratio (Tavenas et al. 1983). However, at Saint Alban, the deposit exhibits a reducing clay fraction and decreasing plasticity with depth as the soil progressively changes from a clay into a silty material; as a result, the effect of reducing void ratio is compensated by changes in void shape and tortuosity so that the in-situ permeability is nearly constant with with both depth and void ratio with a value of about $4 \times 10^{-9} \mathrm{~m} / \mathrm{s}$ (Tavenas et al. 1983). Based on Tavenas et al. (1983) the ratio of horizontal to vertical hydraulic conductivity is very close to unity. (1)

\section{Geometry, construction and modelling of the test embankment}

A plan view and typical cross section of the reinforced embankment are shown in Figs. 2a and 2b, respectively. According to Busbridge et al. (1985), after the subsurface instrumentation (including piezometers, settlement plates, vertical extensometers, and inclinometers) was installed and allowed to stabilize; embankment fill material was placed with the construction rate of $0.6 \mathrm{~m} /$ day. The embankment fill material was a uniform medium to coarse sand with a friction angle of about $34^{\circ}$. The unit weight of the fill material was measured by means of a portable nuclear density test apparatus with the average of $16.9 \mathrm{kN} / \mathrm{m}^{3}$. The embankment side slopes were maintained at a gradient of 1.5:1 (horizontal:vertical). Three side slopes of the embankment were stabilized with the extra $1.5 \mathrm{~m}$ high berm so that any failure was forced to the side where the instrumentation was concentrated. A hig density polyethylene geogrid, Tensar SR-2, was selected for the basal reinforcement. The tensile strength of the geogrid at high strain rates is 79 $\mathrm{kN} / \mathrm{m}$-width. Two horizontal layers of the geogrid were incorporated at the base of the embankment. The lower layer was placed directly at the ground surface and the upper layer was 
placed inside the fill material at elevation of $1.5 \mathrm{~m}$ above the ground surface. Figure $2 \mathrm{a}$ and $2 \mathrm{~b}$ only show the location of instrumentation used to obtain the data that will be compared with the results from numerical analyses - full details of instrumentation are given by Busbridge et al. (1985). The reinforced embankment failed at a height of about $6.1 \mathrm{~m}, 10$ days after the start of the construction.

The finite element mesh used to model the embankment and foundation soil is shown in Fig. 3. The far field boundaries were assumed to be smooth/rigid boundaries. The bottom boundary (the sand) was assumed to be rough/rigid with free drainage. The finite element mesh consisted of 3386 of six-noded triangle elements (6121 nodes) to model layers of soft clay deposits and embankment fill materials. The geogrid reinforcement was modeled using twonoded bar elements. Two-noded rigid-perfectly plastic interface elements proposed by Rowe and Soderman (1985) were used to model the fill/reinforcement and fill/foundation interfaces. A small strain finite element analysis was performed.

\section{Constitutive model for rate-sensitive structured clay and material parameters}

The following provides a brief summary of the model used in this study. Full details regarding the derivation of the constitutive model, the state dependent fluidity parameters concept and the damage law are given by Hinchberger and Qu (2009) and Qu (2008).

\section{Overstress elasto-viscoplasticity}

The Hinchberger and Qu (2009) model is fully coupled with Biot's (1941) consolidation theory and incorporates Perzyna's (1963) theory of overstress viscoplasticity. The derivation of the 

failure envelope and concepts drawn from critical state soil mechanics.

94 equation can be expressed in terms of strain-rate tensor:

$\dot{\varepsilon}_{i j}=\frac{\dot{S}_{i j}}{2 G}+\frac{1}{3 K} \dot{\sigma}_{i i}+\gamma^{v p}\left(\varepsilon_{d}\right)\langle\phi(F)\rangle \frac{\partial f}{\partial \sigma_{i j}}$

where $S_{i j}$ is deviatoric stress; $G$ is shear modulus; $\sigma_{i i}$ is summation of the principal stresses; $K$ is bulk modulus; $\gamma^{v p}\left(\varepsilon_{d}\right)$ is the state-dependent viscoplastic fluidity parameter (to be discussed in the following subsection) and $\varnothing(F)$ is a flow function that can be expressed in term of overstress as:

$99 \phi(F)=\left(\frac{\sigma_{m y}^{\prime(s)}+\sigma_{o s}^{\prime(d)}}{\sigma_{m y}^{\prime(s)}}\right)^{n}-1$

where $\sigma_{o s}^{(d)}$ is overstress, defined as the distance between dynamic and static yield surface at the current stress state (Rowe and Hinchberger 1998); $n$ is strain rate exponent. $\sigma_{m}^{\prime}-\sqrt{2 J_{2}}$ space can be expressed as:

$f=\left(\sigma_{m}^{\prime}-l\right)^{2}+2 J_{2} R^{2}-\left(\sigma_{m y}^{\prime}-l\right)^{2}=0$

105 where $l$ is a mean effective stress corresponding to the center of the ellipse; $R$ is the ratio

106 between major and minor axis of the ellipse; and ${\sigma^{\prime}}_{m y}$ is the intercept of the ellipse with the $\sigma_{m}^{\prime}$ axis. Drucker-Prager failure criterion having a slope of $M_{N / C}$ and $M_{O / C}$ governs the failure of the model for the normally and overly consolidated clay, respectively. 
111 The state-dependent fluidity concept introduces a new parameter, $\omega_{o}$, to mathematically define

112 the structure of the soil (Hinchberger and Qu 2009).

$113 \omega_{o}=\left(\frac{\gamma_{i}^{v p}}{\gamma_{s}^{v p}}\right)^{1 / n}$

114 where; $\gamma_{s}^{v p}$ is fluidity of the undisturbed clay fabric, $\gamma_{i}^{v p}$ is fluidity of the destructed clay fabric

115 and $n$ is strain rate exponent. Next, the concept of the damage strain, $\varepsilon_{d}$, (Rouainia and Wood

116 2000) is employed to define the transition from an initially highly viscous state (structured state)

117 to a more fluid destructured state. The damage strain is expressed as:

$118 d \varepsilon_{d}=\sqrt{(1-A)\left(d \varepsilon_{v o l}^{v p}\right)^{2}+A\left(d \varepsilon_{s}^{v p}\right)^{2}}$

119 where; $d \varepsilon_{d}$ is the incremental damage strain, $d \varepsilon_{v o l}^{v p}$ and $d \varepsilon_{s}^{v p}$ are the plastic volumetric and

120 plastic shear strain, respectively. $A$ is a weighting parameter, which is assumed to be 0.5 similar

121 to Baudet and Stellebrass (2004). Finally, the exponential damage law is introduced to describe

122 rate of soil structure degradation (Hinchberger and Qu 2009), expressed as:

$123 \omega\left(\varepsilon_{d}\right)=\left[1+\left(\omega_{o}^{n}-1\right) \exp \left(-\alpha \cdot \varepsilon_{d}\right)\right]^{1 / n}$

124 where; $\alpha$ is a material parameter governing the rate of destructuration, $\varepsilon_{d}$ is a damage strain,

$125 \omega_{o}$ defines the initial structure and $\omega\left(\varepsilon_{d}\right)$ describes the state-dependent structure level.

126 Accordingly, the fluidity parameter is a function of damage strains as given by:

$127 \quad \gamma^{v p}\left(\varepsilon_{d}\right)=\frac{\gamma_{i}^{v p}}{\omega^{n}\left(\varepsilon_{d}\right)}$

128 where; $\gamma^{v p}\left(\varepsilon_{d}\right)$ defines state-dependent fluidity of the clay fabric. Thus the viscoplastic strain-

129 rate tensors can be expressed as: 
132 strain that can be developed and allows overstress to be built up relative to the static yield

133 surface (destructured/ remolded state). However, with increasing damage plastic strain, the

134 viscosity of the soil decreases (increasing the structural fluidity) to simulate the breaking down

135 of the bond between soil particles. As a result, soil strength decreases and eventually reaches a

136 completely destructured state strength (the critical state).

137 The change in hydraulic conductivity of soft clay during loading is taken to be a function

138 of current void ratio (Taylor 1942) as:

$k_{v}=k_{v o} \exp \left(\frac{e-e_{o}}{C_{k}}\right)$

140 where; $k_{v o}$ is the initial in-situ hydraulic conductivity assumed as $4 \times 10^{-9} \mathrm{~m} / \mathrm{s}$ (Tavenas et al.

141 1983); $e_{o}$ is the initial void ratio as estimated from the soil profile and $C_{k}$ is hydraulic

142 conductivity change index. The value of $C_{k}=0.22 e_{o}$ and a ratio of horizontal to vertical

143 hydraulic conductivity of unity: (i.e., $k_{h} / k_{v}=1$ ) for Saint Alban clay were selected based on

144 the literature (Tavenas et al. 1983).

\section{Embankment fill, reinforcement and interfaces parameters}

147 The granular soil used for the embankment fill had a unit weight $\gamma=16.9 \mathrm{kN} / \mathrm{m}^{3}$ (Busbridge et al.

148 1985). The nonlinear elastic behaviour of the fill was modelled using Janbu's (1963) equation:

$149 \frac{E}{P_{a}}=K_{s}\left(\frac{\sigma_{3}}{P_{a}}\right)^{m}$ 
where $E$ is the Young's modulus; $P_{a}$ is the atmospheric pressure; $\sigma_{3}$ is the minor principal stress

151 and $K_{s}$ and $m$ are material constants selected to be 300 and 0.5 , respectively (Rowe and

152 Hinchberger 1998). The yielding of the sand fill was model using the Mohr-Coulomb failure

153 criterion with a friction angle $\varnothing^{\prime}=34^{\circ}$, and the plastic flow was governed by non-associated flow

154 rule with dilatancy angle $\psi=6^{\circ}$.

155 Two types of constitutive model (i) the elastic bar elements and (ii) the nonlinear 156 viscoelastic bar element (Zhang and Moore 1997) were used to model the short-term

157 performances of reinforcement in this study. The axial tensile stiffness, $J=300 \mathrm{kN} / \mathrm{m}$, of the

158 elastic bar element was determined from the isochronous load strain curves as shown in Fig. 4

159 (Busbridge et al. 1985).

160 The governing equation for the nonlinear viscoelastic bar element (i.e. multi-Kelvin

161 elements model) used in this study can be expressed in terms of strain rate as:

162

$163 \quad \dot{\varepsilon}=\frac{\dot{\sigma}_{T}}{a_{o} \exp \left(-a_{1} \sigma_{T}^{3}\right)}+\sum_{i}^{n_{K}}\left\{\frac{\sigma_{T}}{E_{i} \tau_{i}}-\frac{\varepsilon_{i}^{v}}{\tau_{i}}\right\}$

164 where; $\sigma_{T}$ is tensile stress of the independent spring; $a_{o}$ and $a_{1}$ are material constants; $n_{K}$ is the

165 number of Kelvin elements; $\tau_{i}=\eta_{i} / E_{i}$ is the retardation time; $E_{i}$ and $\eta_{i}$ are the spring modulus

166 (stiffness of geosynthetic reinforcement) and the dashpot viscosity of the $i^{\text {th }}$ Kelvin element,

167 respectively. The following equations are proposed to reduce the number of material constants

168 (Zhang and Moore 1997):

169

170

$E_{i}=\delta^{i-1} E_{1}$ and $\tau_{i}=\beta^{i-1} \tau_{1}$ 
where; $E_{1}$ and $\tau_{1}$ are the material constants.

The required seven material constants are $a_{o}, a_{1}, \delta, \beta, E_{1}, \tau_{1}$ and $n_{K}$. The constitutive parameters for the nonlinear viscoelastic reinforcement used examined in this study (i.e. HDPE and PET geogrids) were selected based on values givn in the literature for the same products (Li and Rowe 2001). All parameters are also presented in Table 1.

The rigid-plastic joint elements (Rowe and Soderman 1985) used to model the fill/reinforcement interfaces were assumed to be frictional with $\varnothing^{\prime}=34^{\circ}$.

\section{Selection of foundation soil parameters}

The basic soil parameters such as initial void ratio, water content, unit weight and current states of stress were obtained from the soil profile presented in Fig. 1. Poisson's ratio was assumed to be constant for the clay. A value of 0.3 was used based on Tavenas et al. (1974). The critical state parameters (e.g., $\lambda$ and $\kappa$ ) - used to define the hardening rule in model - were selected based on the recommendation of Zdravkovic et al. (2002). The estimated coefficient of earth pressure at rest, $K_{o}$, for a normally consolidated material was taken to be 0.49 based on the established limit-state curves for undisturbed samples (Tavenas et al. 1978; and Zdravkovic et al. 2002). For the overconsolidated crust, the corresponding $K_{o}$ profile was calculated from the Mayne and Kulhawy (1982) formula $\left(K_{o O / C}=K_{o N / C} O C R^{\sin \phi}\right)$.

Specific parameters such as fluidity parameters of the soil, degree of soil structures and rate of soil structure degradation with respect to accumulated plastic strain were calibrated using experimental results. Figure 5 shows the effect of strain rate on the apparent preconsolidation pressure for Saint Alban clay (Leroueil et al. 1988). The strain rate exponent (n) was established from the reciprocal of slope of $\log \left(\sigma_{p}^{\prime}\right)-\log \left(\dot{\varepsilon}_{a}\right)$ relationship (Qu et al. 2010). In addition, the 
relationship between apparent preconsolidation pressure and strain rate can also be used to estimate the fluidity of the undisturbed clay fabric $\left(\gamma_{s}^{v p}\right)$. Qu et al. (2010) derived equations

197 based on strain rate controlled testing and showed that $\gamma_{s}^{v p}=\sqrt{5 / 3} \dot{\varepsilon}_{n v}$; where $\dot{\varepsilon}_{n v}$ is a threshold 198 strain rate which divides soil behaviour between rate-insensitive and rate-sensitive. If soil is 199 subjected to any strain rates faster than the threshold limit, the strain rate effect will be mobilized. However, for Saint Alban clay, the foundation soil still exhibits the effect of strain rate-sensitivity even at strain rates as low as $6 \times 10^{-9} / \mathrm{min}$. Qu et al. (2010) suggested that, in 202 these cases, the threshold strain rate of $6 \times 10^{-9} / \mathrm{min}$ would be adequate to account for the effect 203 of strain rate-sensitivity characteristic over first 25-30 years. Therefore, a threshold strain rate of 204 $6 \times 10^{-9} / \mathrm{min}$ was assumed in this study and the corresponding fluidity of the undisturbed clay fabric $\left(\gamma_{s}^{v p}\right)$ was estimated to be $\gamma_{s}^{v p}=1.3 \times 10^{-9} / \mathrm{min}$.

The structure parameter $\left(\omega_{o}\right)$ can be estimated from either (i) peak versus remolded undrained shear strength or (ii) from intrinsic versus structured preconsolidation pressure $(\mathrm{Qu}$ 2008). In this study, the former approach was employed. Figure 6 shows the stress-strain curves of the unconsolidated undrained test (La Rochelle et al. 1974). From Fig. 6, the structure parameter was estimated to be $\omega_{o}=s_{u-\text { peak }} / s_{u-\text { remolded }}=1.35$. The fluidity of the destructed

211 clay fabric $\left(\gamma_{i}^{v p}\right)$ was calculated using Equation 4. Equation 5 was then used to calculate the 212 magnitude of strain at which the intrinsic state is reached (i.e., refer to Fig. 6). Lastly, from Equation 2136 , the constitutive parameter $\alpha$ governing the rate of destructuration was estimated. All the 214 constitutive soil parameters are summarized in Table 2. The stress-strain behaviour predicted by 215 axisymmetric finite element analysis using state-dependent viscoplastic parameter model 
216 (Hinchberger and Qu 2009) is shown in Fig. 6. Full details of the calculations are presented in 217 Taechakumthorn (2011).

\section{Comparison of calculated and measured responses}

220 The results from the 2D plane strain finite element analyses are compared with field 221 measurements for the geogrid reinforced test embankment at Saint Alban (Busbridge et al. 222 1985), to allow an evaluation of the extended elasto-viscoplastic constitutive model. Due to the highly anisotropic nature of Saint Alban clay, the shape of yield surface used in the analyses was selected to match the soil yield surface and the model yield surface for the applied stress path associated with vertical loading. Figure 7 shows a comparison of the soil yield surface and the modeled yield surface together with the calculated stress path that the soil experienced at location A during construction (see insert in Fig. 7). As demonstrated in Fig. 7, the implemented yield surface matched the in-situ yield surface well for the stress range that the foundation soil experienced (i.e., above the $K_{o}$ line) beneath the crest of the embankment.

To examine the effect of incorporating the soil structure into the model for this particular case study, analyses also were perfumed using the original elasto-viscoplastic model (Rowe and Hinchberger 1998) for comparison with those obtained from the extended elasto-viscoplastic model (Hinchberger and Qu, 2009)..

To evaluate the beneficial effect of geosynthetic reinforcement used in this study, analyses were performed using the structured elasto-viscoplastic soil model assuming (i) elastic reinforcement (with an axial tensile stiffness, $J=300 \mathrm{kN} / \mathrm{m}$, determined from the isochronous load strain curves as shown in Fig. 4), (ii) considering the viscoelastic properties of the high density polyethylene (HDPE) reinforcement actually used to illustrate the effect of reinforcement 
viscosity on short-term stability, (iii) without the use of reinforcement and (iv) with stiffer and less creep susceptible polyester (PET) reinforcement with viscoelastic constitutive parameters, 241 given in Table 1 (based on Li and Rowe 2001).

\section{Structured versus Non-structured elasto-viscoplastic soil model}

244 The benefit of incorporating effect of soil structure and its destructuration into the model is 245 illustrated in Figs. 8 and 9. The original elasto-viscoplastic soil model (Rowe and Hinchberger 246 1998) underestimates vertical settlement at the centerline (Fig. 8) and excess pore water beneath 247 the embankment shoulder (Fig. 9). Moreover, there is no failure of the simulated embankment, 248 even after constructed up to $6.3 \mathrm{~m}$. This is because Rowe and Hinchberger (1998) model cannot 249 capture the de-structuring of the Saint Alban soil. Therefore, soil strength and stiffness remain 250 almost unchanged after yielding which results in smaller deformations.

Because the non-structured elasto-viscoplastic soil model underestimates the overall deformation of the soils; in Fig. 10a and 10b, the prediction of horizontal deformations near the embankment toe (IN-1 and IN-2) seems better than those predicted using structured elastoviscoplastic soil model. Since the non-structured elasto-viscoplastic soil model could not capture the vertical response or pore pressure development for the St Alban soil as well as the structured model, the discussion of the effect of reinforcement below will focus on the results from the structured elasto-viscoplastic soil model (Hinchberger and Qu, 2009).

\section{Failure height and vertical settlement}

260 Assuming the properties of either the elastic reinforcement or the stiffer viscoelastic PET

261 reinforcement, the calculated failure height of the test embankment was $6.0 \mathrm{~m}$, which is close to 
the observed failure height of about $6.1 \mathrm{~m}$. The numerical analyses using viscoelastic HDPE reinforcement as well as those with no reinforcement both gave slightly smaller failure heights of

$2645.9 \mathrm{~m}$. This suggests that for this particular soil the geogrid reinforcement had very little effect on embankment performance. Although there was a slight difference in the calculated failure height due to different types of reinforcement, the calculated settlements at the center line were almost identical. The calculated and observed settlements at the centerline (SP-9) showed good agreement (Fig. 8) with the in-situ measurement - for all types of reinforcement modeled - until the fill thickness reached about $2.4 \mathrm{~m}$ (vertical stress of about $40 \mathrm{kPa}$ ) where there was a rapid change in the load-settlement curve indicating yielding of the foundation soil. From this point, 271 the finite element analyses tend to underestimate the centerline settlement. This is due to the fact 272 that the high initial viscosity of the soil modeled prevents deformations at the beginning stage of 273 loading. However, the differences are modest and the overall trend was well captured. The final 274 settlement at the centerline was also well predicted. The final settlements measured just before 275 failure were $0.23 \mathrm{~m}$ and $0.24 \mathrm{~m}$ for the field measurement and finite element analyses, 276 respectively.

\section{Excess pore water pressure}

279 The data from the piezometer which showed the maximum response, PN-15 (Fig. 2) was used to 280 illustrate the buildup of pore water pressure under the reinforced embankment. The relationship 281 between the excess pore water pressure and the increase in vertical total stress (Fig. 9) showed 282 that the model tended to overestimate the excess pore water pressure at the beginning of loading 283 up to the fill thickness of about $3.9 \mathrm{~m}$ (i.e. the increase of vertical stress of about $65 \mathrm{kPa}$ ). This 284 might be due to the fact that the high initial viscosity of the model (i.e. soil structure) restrains 
soil movement as discussed earlier. Consequently, it delayed the soil consolidation and hence reduced the rate of excess pore water dissipation at early time compared with the observed field behaviour.

In the field, as the total vertical stress increased beyond about $60 \mathrm{kPa}$, the slope of the observed pore pressure response significantly increased compared with at the earlier stage of loading. The slope of applied stress against excess pore pressure relationship exceeded unity suggesting that destructuring/collapsing of the clay fabric. This caused the rapid increase in excess pore water pressure at a rate which exceeded the rate of consolidation during this period up to failure. The model captured some, but not all, of this change because the viscosity of the model still prevented the rapid deformation (collapse) of the soil. As a result, the field excess pore pressure response rose above the calculated values at the later stage of loading. Despite some limitations, the agreement between the field measurement and the predicted excess pore water pressure is still considered reasonable.

Figure 9 shows that the predicted excess pore water pressures were essentially the same for all four analyses (i.e. no reinforcement, elastic reinforcement, viscoelastic HDPE reinforcement, and the stiffer viscoelastic PET reinforcement) implying that neither the particular geogrid reinforcement that was used nor other commonly used reinforcement would significantly contribute to improving the stability of the embankment examined in this study.

\section{Horizontal deformation}

The shape of the deformed inclinometer casings at IN-1 and IN-2 (Fig. 2), corresponding with the centerline surcharge about $77 \mathrm{kPa}$ (Busbridge et al. 1985), are presented together with the calculated results from finite element analyses in Fig. 10a and 10b, respectively. In all cases, the 
calculated horizontal deformation profiles are significantly greater than the observed values. This is consistent with previous published experience using small strain analysis where numerical methods have tended to overestimate horizontal deformations (Poulos 1972; Tavenas et al. 1979;

311 Rowe et al. 1996; and Hinchberger and Rowe 1998). The difference between calculated and 312 measured horizontal deformation may be caused by the combined effect of significant rotation of 313 principal stress under the embankment slope and the highly anisotropic characteristics of the 314 foundation soil.

315 The calculated rate of increase in horizontal deformation (Fig. 11) accelerated when the 316 centerline surcharge pressure exceeded about $77 \mathrm{kPa}$, which agrees well with what was observed 317 (Busbridge et al. 1985). The results presented in Fig. 10a, 10b and 11 show some slight 318 differences in the prediction of horizontal deformation for all cases. However, the differences are 319 practically insignificant.

\section{Performance of geogrid reinforcement}

According to the summary report (Busbridge et al. 1985), the load and strain mobilized in the reinforcement were relatively small during construction and up to failure. The maximum loads measured in the geogrid under the crest of the reinforced embankment were 9.1 and $6.4 \mathrm{kN} / \mathrm{m}$ at the lower and upper level of reinforcement, respectively. The maximum reinforcement loads calculated at the same location using finite element analysis were 9.8 and $8.3 \mathrm{kN} / \mathrm{m}$ at the lower

327 and the upper level of reinforcement, respectively. Figure 12 shows the development of the 328 reinforcement loads and strain with the vertical stress at the centerline of the embankment. 329 During the construction of the embankment, only low reinforcement loads were observed in the 330 field for both the lower and upper layer of geogrid which is consistent with the calculations from 
the finite element analyses. However the field report indicated that there was a rapid straining

332 just before failure and the back-calculated reinforcement rupture load exceeded $45 \mathrm{kN} / \mathrm{m}$ and 333 probably approached $60 \mathrm{kN} / \mathrm{m}$ (Busbridge et al. 1985). The rapid increase in load was likely 334 associated with major destructuring, and consequent strength loss, of this highly sensitive clay at 335 failure. The reinforcement was not sufficient to sustain the loads when the foundation soil failed 336 and likely tore. The constitutive model examined here indicated the onset of failure but was not 337 able to capture the behaviour during failure.

\section{Conclusions}

The results from finite element analyses conducted using elasto-viscoplastic constitutive models with/without incorporating the state-dependent fluidity parameter concept and damage

342 law were compared with field observations for the reinforced test embankment constructed on sensitive Champlain clay deposit at Saint Alban, Quebec. The structured elasto-viscoplastic model (Hinchberger and Qu 2009) was shown to better capture many aspects of the embankment performance compared to the original elasto-viscoplastic model. This was because the original elasto-viscoplastic soil model could not capture the effect of soil structure and the destructuration process. As a result, the model could not simulate the strain softening behaviour of the Saint Alban clay. Consequently, it tended to underestimates deformations of the Saint Alban clay, examined in this study. The following conclusions relate to the predictions of reinforced embankment behavior obtained using the structured elasto-viscoplastic soil model.

The vertical settlement at the centerline of the embankment was well predicted during the early stages of loading (up to $2.4 \mathrm{~m}$ of fill thickness). As the load increased, the model tended to 
somewhat underestimate the vertical settlement at the centerline. However, the trend and the

354 final vertical settlement just before failure were in good agreement.

The calculated excess pore water pressure response overestimated the field measurement at the early stages of construction. As failure was approached, the field response showed a significant increase in the rate of excess pore water pressure development. This phenomenon and its consequences were not well captured because the initial modeled soil viscosity used to simulate the effect of soil structure prevented the rapid decrease in void ratio and hence consolidation of the soil. This is a fundamental limitation of this particular model. Even though this use of soil viscosity to model de-structuring had some limitations, the proposed model was 362 still able to provide reasonable estimates of the excess pore water pressure response.

The finite element analyses over-predicted the horizontal deformation profiles. The 364 difference between calculated and measured horizontal deformation might cause by the 365 combined effect of significant rotation of principal stress under the embankment slope combined 366 with the anisotropic characteristics with respect to strength and stiffness-of the foundation soil. 367 The analyses, however, did indicate the point at which the rate of horizontal toe movement 368 started to accelerate. To provide adequate predictions of the horizontal deformation where there 369 is significant rotation of principal stress, the effects of strength and stiffness anisotropy need to 370 be addressed in the constitutive model. With respect to the response of reinforcement, the 371 structured elasto-viscoplastic soil model provided good agreement with the observed field data in 372 terms of reinforcement load and strain prior to failure.

The effect of reinforcement was explored numerically and it was found that the 374 calculated response with and without the geogrid reinforcement and with stiffer and less creep 375 susceptible PET reinforcement were almost identical giving only minor differences. It is 
concluded that for this particular embankment being studied (i.e. constructed on highly sensitive 377 clay with a heavily overconsolidated crust at a very fast construction rate) the geogrid 378 reinforcement use had no significant beneficial effect in terms of redistributing shear stress in 379 foundation soil. This is likely because the reinforcement was not sufficiently stiff relative to the 380 overconsolidated crust to play any significant role prior to the onset of foundation failure and not 381 strong enough to control the failure once failure of the foundation soil was initiated.

383 Acknowledgements

384 The research reported in this paper was funded by a research grant from the Natural Sciences and 385 Engineering Research Council of Canada (NSERC). The authors would like to thank Dr. 386 Hinchberger and Dr. Qu for their guidance regarding implementation of the structured elasto387 viscoplastic soil model used in this study. 


\section{References}

Baudet, B., and Stallebrass, S. 2004. A constitutive model for structured clays. Geotechnique, 54(4): 269278.

Biot, M.A. 1941. General theory of three-dimensional consolidation. Journal of Applied Physics, 12: 155164.

Burland, J.B. 1990. On the compressibility and shear strength of natural clays. Geotechnique, 40(3): 329378.

Busbridge, J.R., Chan, P., Milligan, V., La Rochelle, P.R., and Lefebvre, L.D. 1985. The effect of geogrid reinforcement in the stability of embankments on a soft sensitive Champlain clay deposit. Summary report prepared for Transportation Development Centre, Transport Canada.

Carter, J.P., and Balaam, N.P. 1990. AFENA- A general finite element algorithm: Users manual. School of Civil Engineering and Mining Engineering, University of Sydney, N.S.W. 2006, Australia.

Chen, W.F., and Mizuno, E. 1990. Nonlinear Analysis in Soil Mechanics: Theory and Implementation. Elsevier Science Publishing Company Inc., New York, U.S.A.

Hinchberger, S.D. 1996. The behaviour of reinforced and unreinforced embankments on soft ratesensitive foundation soils. Ph.D. thesis, Department of Civil Engineering, The University of Western Ontario, London, Ont.

Hinchberger, S.D., and Qu, G. 2009. A constitutive approach for rate-sensitive structured clay, Canadian Geotechnical Journal, 46(6): 609-626.

Hinchberger, S.D., and Rowe, R.K. 1998. Modelling the rate-sensitive characteristics of the Gloucester foundation soil. Canadian Geotechnical Journal, 35(5): 769-789.

Janbu, N. 1963. Soil compressibility as determined by oedometer and triaxial tests. In Proceedings of the European Conference on Soil Mechanics and Foundation Engineering, Wiesbaden, Germany. 1:19-25.

Kim, Y.T., and Leroueil, S. 2001. Modeling the viscoplastic behaviour of clays during consolidation: Application to Berthierville clay in both laboratory and field conditions. Canadian Geotechnical Journal, 38(3): 484-497.

La Rochelle, P., Trak, B., Tavenas, F., and Roy, M. 1974. Failure of a test embankment on a sensitive Champlain clay deposit. Canadian Geotechnical Journal, 11(1): 142-164.

Lefebvre, G., and Pfendler, P. 1996. Strain rate and pre-shear effects in cyclic resistance of soft clay. Journal of Geotechnical Engineering, ASCE, 122(1): 21-26

Lefebvre, G., Ladd, C. C., and Pare, J. J. 1988. Comparison of field vane and laboratory undrained shear strength in soft sensitive clays. In Vane shear strength testing in soils (ed. A. F. Richard), ASTM STP 1014: 233-246 Philadelphia. 
Leroueil, S., and Vaughan, P.R. 1990. The general and congruent effects of structure in natural soils and weak rocks. Geotechnique, 40(3): 467-488.

Leroueil, S., Kabbaj, M., and Tavenas, F. 1988. Study of the validity of a $\sigma^{\prime}-\varepsilon_{\mathrm{v}}-\varepsilon_{\mathrm{v}}$ rate model in in-situ conditions. Soils and Foundations, 28(3): 13-25.

Leroueil, S., Samson, L., and Bozozuk, M. 1983. Laboratory and field determination of preconsolidation pressures at Gloucester, Canadian Geotechnical Journal, 20(3); 477-490

Li, A.L., and Rowe, R.K. 2001. Influence of creep and stress-relaxation of geosynthetic reinforcement on embankment behaviour. Geosynthetics International, 8(3), 233-270.

Lo, K.Y., and Hinchberger, S.D. 2006. Stability analysis accounting for macroscopic and microscopic structures in clays. In Proceeding of 4th International Conference on Soft Soil Engineering. Vancouver, Canada: 3-34.

Malandraki, V., and Toll, D. 2000. Drained probing triaxial tests on a weakly bonded artificial soil. Geotechnique, 50(2): 141-151.

Mayne, P. W., and Kulhawy, F. H. 1982. $\mathrm{K}_{\mathrm{o}}$-OCR relationship in soils. Journal of Geotechnical Engineering, ASCE, 108(6): 851-872

Perzyna, P. 1963. The constitutive equations for rate-sensitive plastic materials" Quarterly of Applied Mathematics, 20(4): 321-332.

Poulos, H. G. 1972. Difficulties in predicting horizontal deformation of foundation. Journal of the Soil Mechanics and Foundations Division, ASCE, 98(SM8): 843-848.

$\mathrm{Qu}, \mathrm{G} .2008$. Selected issues on the performance of embankments on clay foundations. $\mathrm{PhD}$ thesis, the University of Western Ontario, London, Canada

Qu, G., Hinchberger, S. D., and Lo, K. Y. 2010 Evaluation of the viscous behaviour of clay using generalised overstress viscoplastic theory. Geotechnique, 60(10): 777-789.

Quigley, R.M. 1980. Geology, mineralogy and geochemistry of Canadian soft soils: a geotechnical perspective. Canadian Geotechnical Journal, 17(2): 261-285.

Rocchi, G., Fontana, M., and Da Prat, M. 2003. Modeling of natural soft clay destruction processes using viscoplasticity theory. Geotechnique, 53(8): 729-745.

Rouainia, M., and Wood, D.M. 2000. Kinemetic hardening constitutive model for natural clays with loss of structure. Geotechnique, 50(2): 153-164.

Rowe, R.K., and Hinchberger, S.D. 1998. The significance of rate effects in modelling the Sackville test embankment. Canadian Geotechnical Journal, 33(3): 500-516.

Rowe, R.K., and Soderman, K.L. 1985. An approximate method for estimating the stability for geotextiles reinforced embankments. Canadian Geotechnical Journal. 22(3): 392-398. 
Rowe, R.K., Gnanendran, C.T., Landva, A.O., and Valsangkar, A.J. 1996. Calculated and observed behaviour of a reinforced embankment over soft compressible soil. Canadian Geotechnical Journal, 33(2): 324-338.

Taechakumthorn, C. 2011. Effect of reinforcement and soil viscosity on the behaviour of embankments over soft soil. PhD Thesis. Queen's University, Kingston, Canada.

Tavenas, F., Jean, P., Leblond, P., and Leroueil, S. 1983. The permeability of natural soft clays. Part II: Permeability characteristics, Canadian Geotechnical Journal, 20(4): 645-660.

Tavenas, F., Leroueil, S., La Rochelle, P., and Roy, M. 1978. Creep behaviour of an undisturbed lightly overconsolidated clay. Canadian Geotechnical Journal, 15(3): 402-423.

Tavenas, F., Mieussens, C., and Bourges, F. 1979. Lateral displacements in clay foundations under embankments. Canadian Geotechnical Journal, 16(4): 535-550.

Taylor, D.W. 1942. Research on consolidation of clay. Department of Civil and Sanitary Engineering, M.I.T., Publication, 82: 1-147.

Torrance, J.K. 1999. Physical, chemical and mineralogical influences on the rheology of remolded lowactivity sensitive marine clay. Applied Clay Science, 14: 199-223.

Trak, B., La Rochelle, P., Tavenas, F., Lerloueil, S., and Roy, M. 1980. A new approach to the stability analysis of embankments on sensitive clays. Canadian Geotechnical Journal, 17(4): 526-544.

Vaid, Y.P., Robertson, P.K., and Campanella, R.G. 1979. Strain rate behaviour of Saint-Jean-Vianney clay. Canadian Geotechnical Journal, 16(1): 34-42.

Zdravkovic, L., Potts, D. M., and Hight, D. W. 2002. The effect of strength anisotropy on the behaviour of embankments on soft ground. Geotechnique, 52(6): 447-457

Zhang, C., and Moore, I.D. 1997. Nonlinear mechanical response of high density polyethylene. Part I: experimental investigation and model evaluation. Polymer Engineering and Science, 37(2): 404-413. 
Table 1. Nonlinear viscoelastic model parameter for reinforcement (Li and Rowe 2001)

\begin{tabular}{cccccccc}
\hline & \multicolumn{7}{c}{ Material constants } \\
\cline { 2 - 8 } Reinforcement material & $\begin{array}{c}a_{o} \\
\mathrm{kN} / \mathrm{m})\end{array}$ & $\begin{array}{c}a_{1} \\
(\mathrm{~m} / \mathrm{kN})\end{array}$ & $\delta$ & $\beta$ & $\begin{array}{c}E_{1} \\
(\mathrm{kN} / \mathrm{m})\end{array}$ & $\begin{array}{c}\tau_{1} \\
(\text { hour })\end{array}$ & $n_{K}$ \\
\hline HDPE & 1050 & $7 \times 10^{-6}$ & 1 & 10 & 3000 & 0.02 & 9 \\
PET & 1800 & $2 \times 10^{-7}$ & 1.2 & 10 & 60000 & 0.07 & 7 \\
\hline
\end{tabular}

Table 2. Elliptical cap soil model parameters

Soil Parameter

Failure envelope $M_{N / C}$ 0.9

Failure envelope $M_{O / C}$

0.21

Aspect ratio $R$

0.42

Compression index $\lambda$

0.57

Recompression index $\kappa$

0.03

Coefficient of earth pressure at rest $K_{o}$

0.49

Poisson's ratio $v$

0.3

Hydraulic conductivity $k_{v o}(\mathrm{~m} / \mathrm{s})$

$4 \times 10^{-9}$

Intrinsic viscoplastic fluidity $\gamma_{i}^{v p}\left(\mathrm{hr}^{-1}\right)$

$7 \times 10^{-4}$

Strain rate exponent $n$

Structure parameter $\omega_{o}$

1.35

Parameter controlling rate of destructuration $\alpha$ 


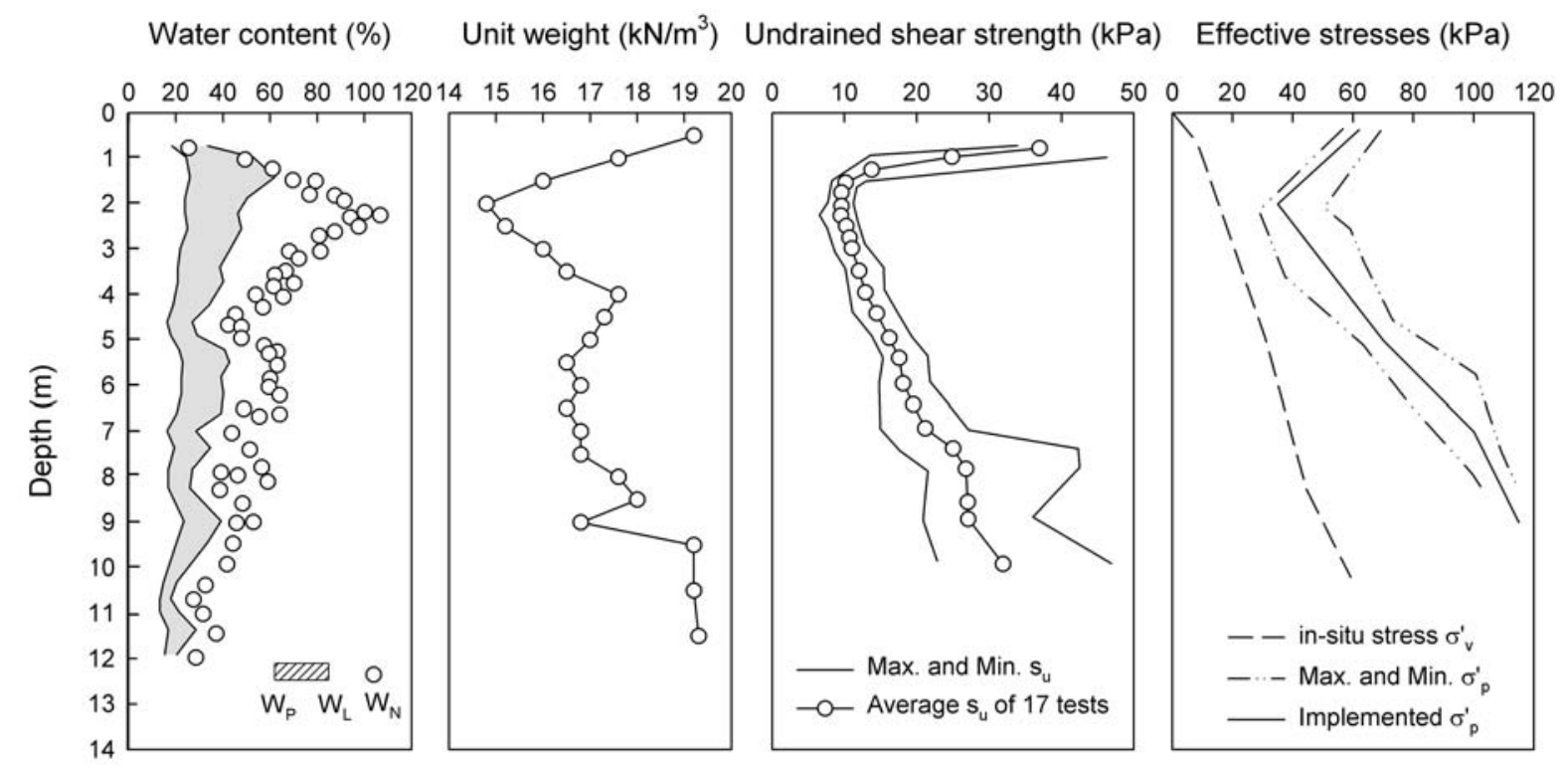

Figure 1. Typical soil profiles of the test site at Saint Alban, Quebec (modified from Trak et al. 1980) 


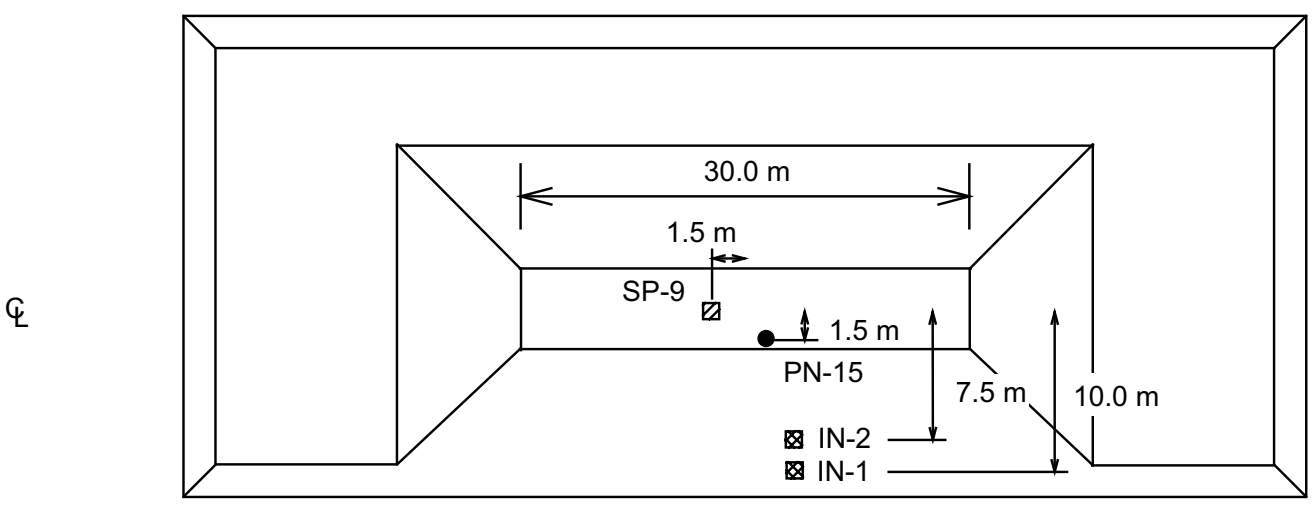

$$
\begin{array}{ll}
\text { Notations } \\
\text { SP } & \text { Settlement Plate } \\
\text { PN } & \text { Pneumatic Piezometer } \\
\text { IN } & \text { Inclinometer }
\end{array}
$$

Not to scale

(a)

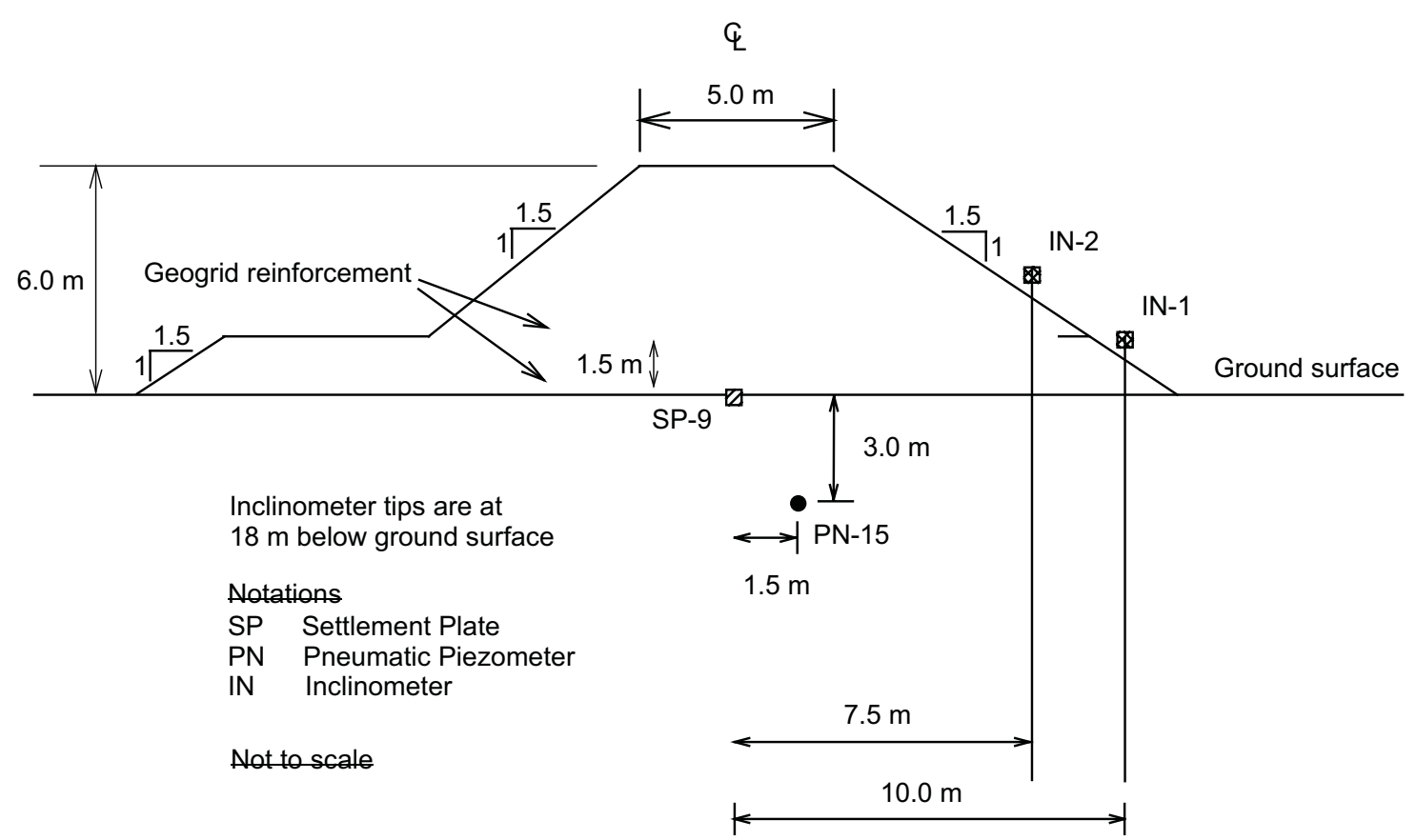

(b)

Figure 2. Plan view and cross sectional profile of reinforced test embankment (modified from Busbridge et al. 1985) 


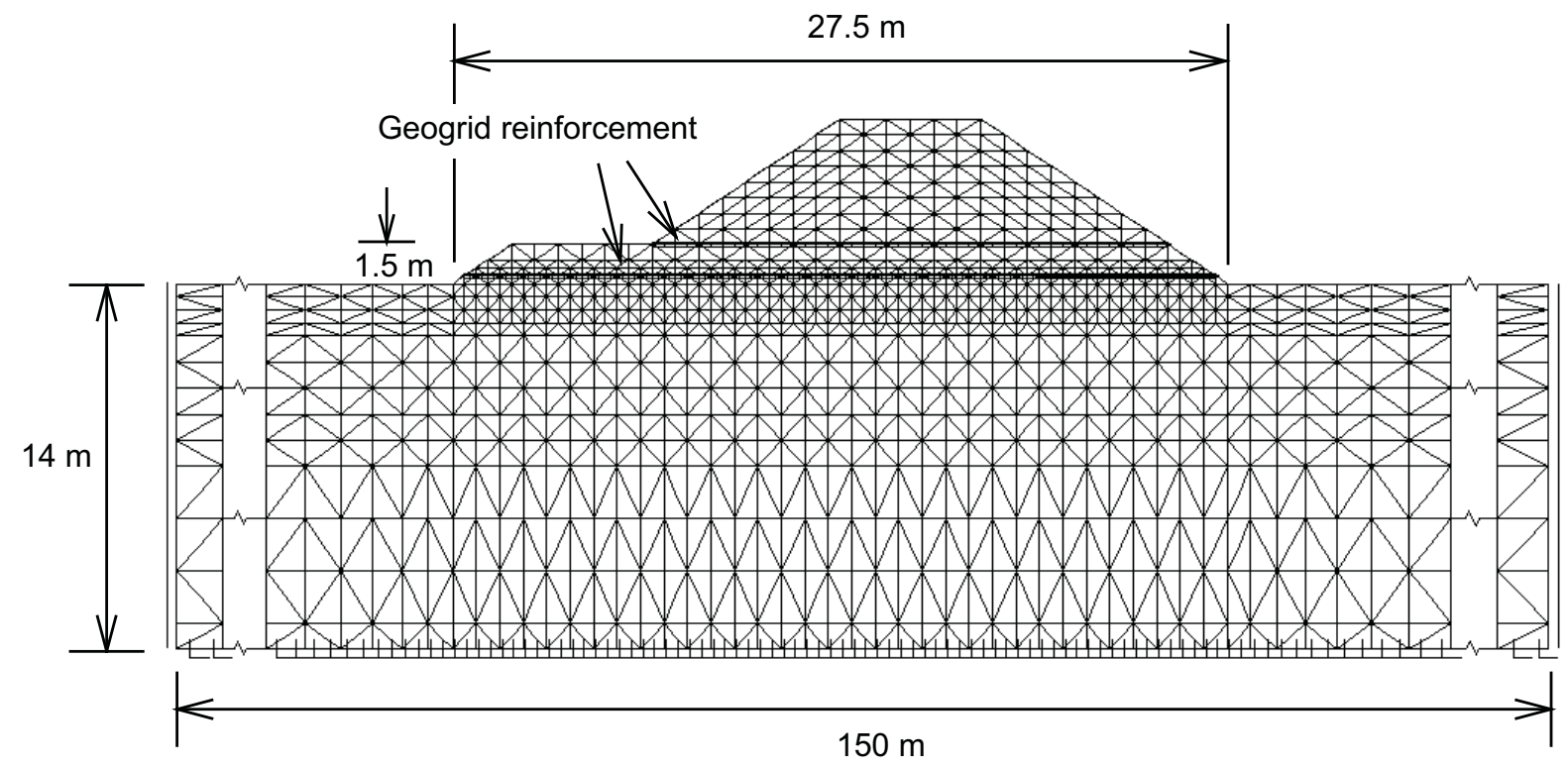

Figure 3. Finite element mesh for the reinforced test embankment examined 


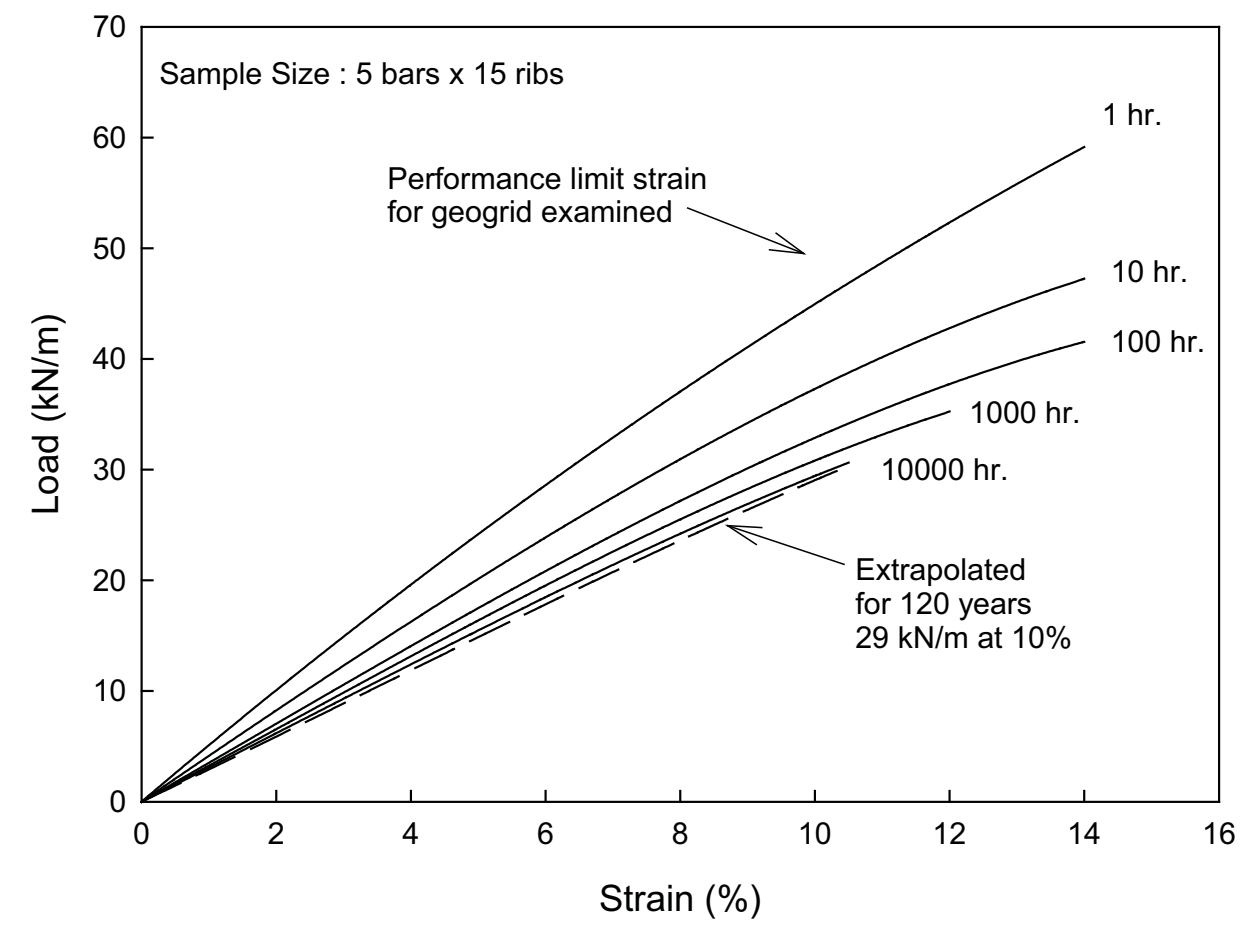

Figure 4. Isochronous load strain curves of Tensar SR2 geogrids (modified from Busbridge et al. 1985) 


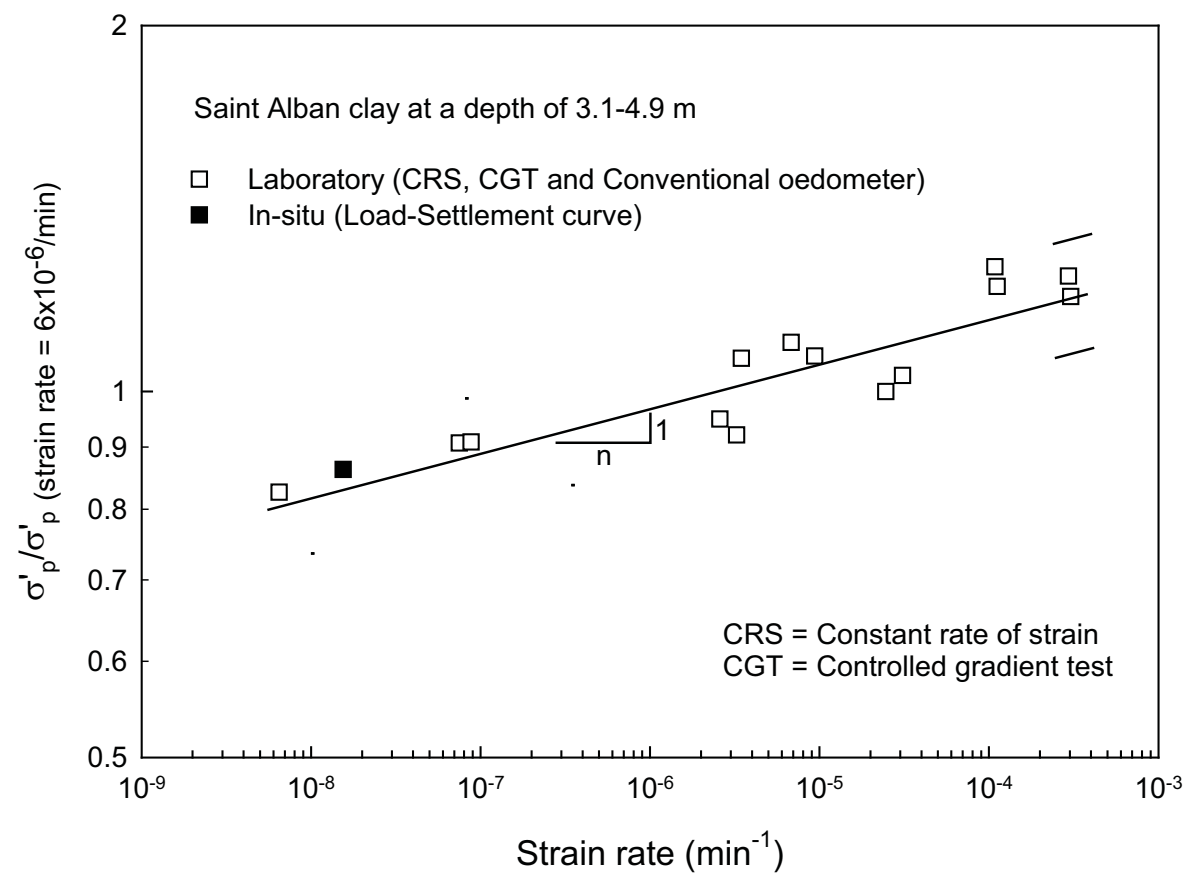

Figure 5. Effect of strain rate on the preconsolidation pressure of the Saint Alban clay (modified from Leroueil et al. 1988) 


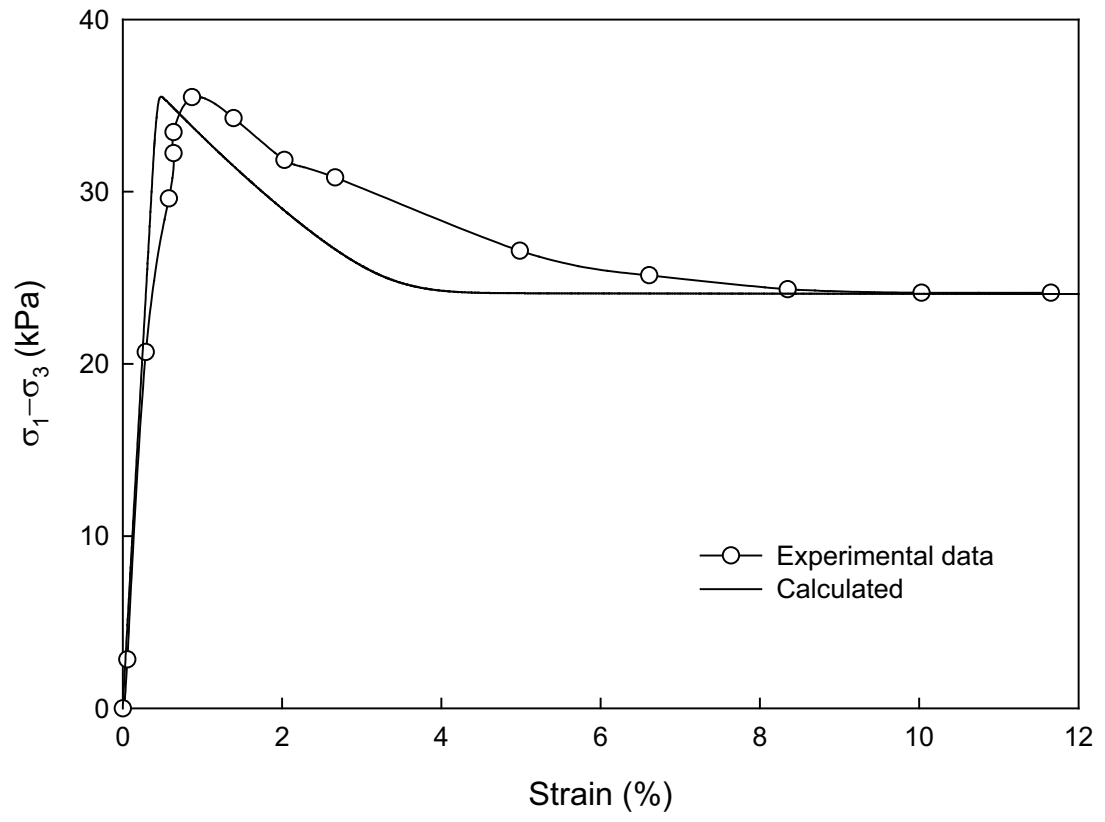

Figure 6. Results from the unconsolidated undrained compression test on Saint Alban clay and calculated value using the parameters adopted in this paper (experimental data from La Rochelle et al. 1974) 


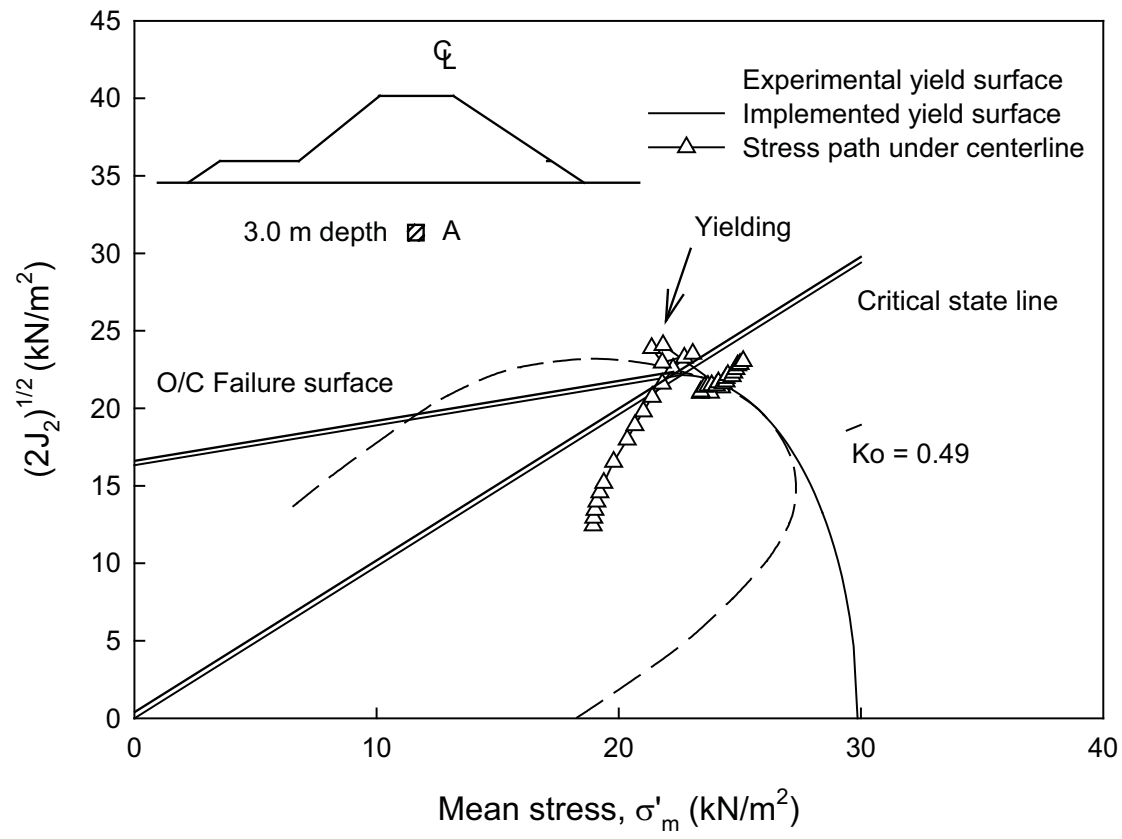

Figure 7. Comparison between experimental and implemented yield surface and stress path of the soil under centerline of the reinforced embankment (experimental data from Tavenas et al. 1974) 


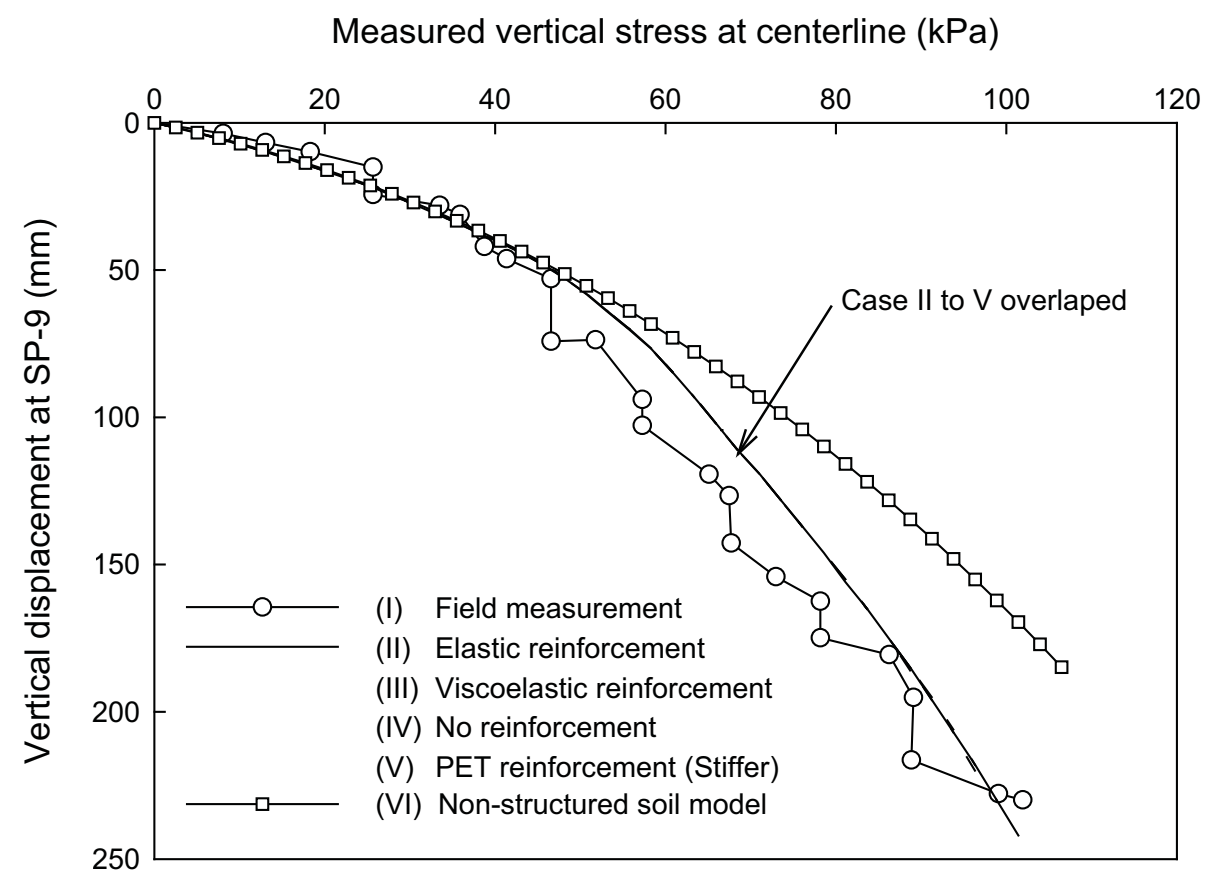

Figure 8. Vertical settlement of the reinforced embankment at settlement plate SP-9 (field data from Busbridge et al. 1985) 


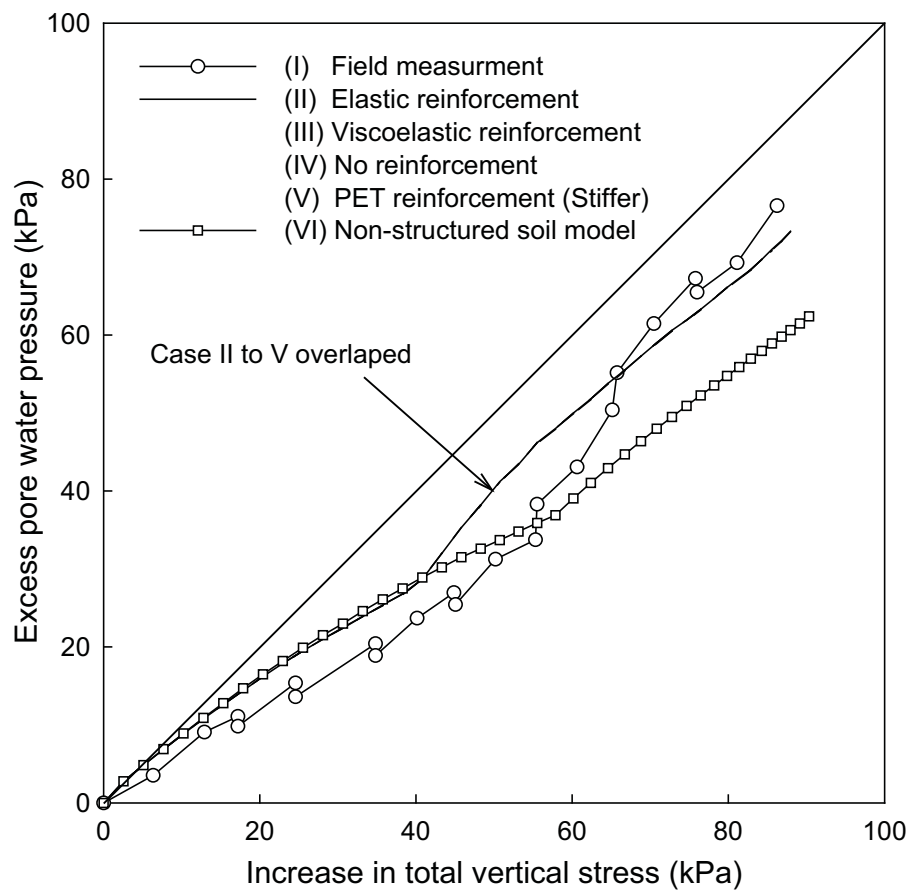

Figure 9. Relationship between increase in total vertical stress and excess pore water pressure at pizometer PN-15 (field data from Busbridge et al. 1985) 


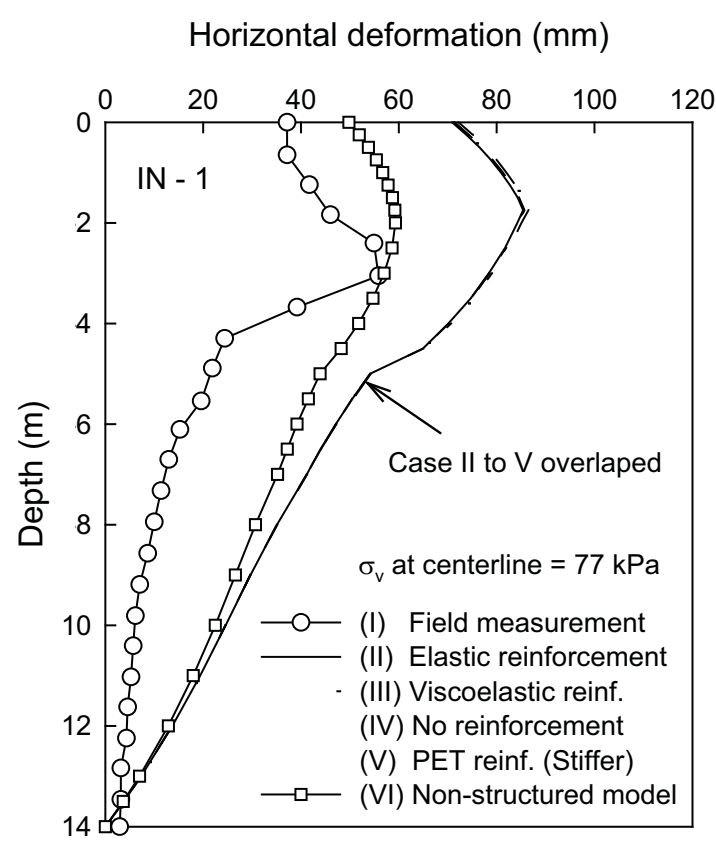

(a)
Horizontal deformation (mm)

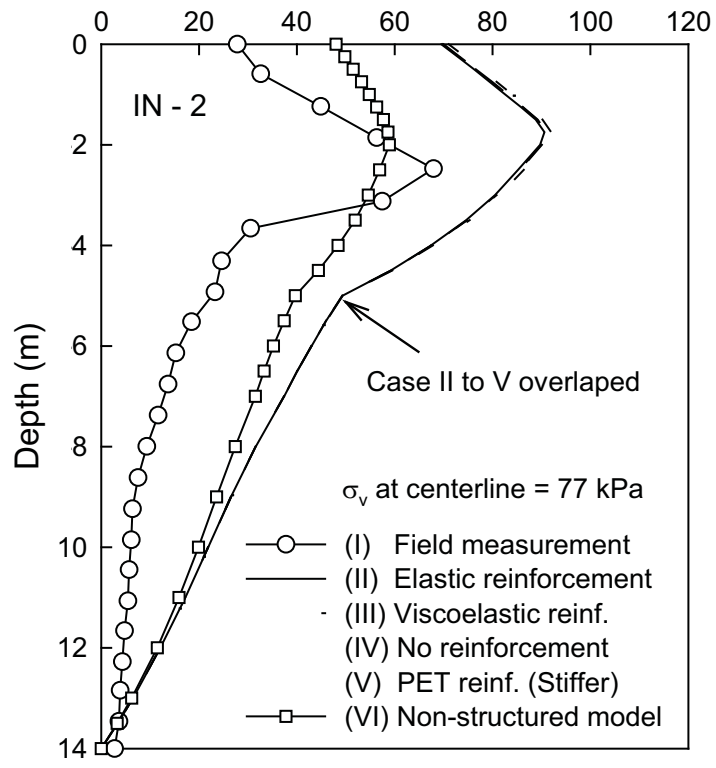

(b)

Figure 10. Comparison of the horizontal deformation profiles at a surcharge of $77 \mathrm{kPa}$ (Fill height $=4.5 \mathrm{~m}$ : field data from Busbridge et al. 1985) 


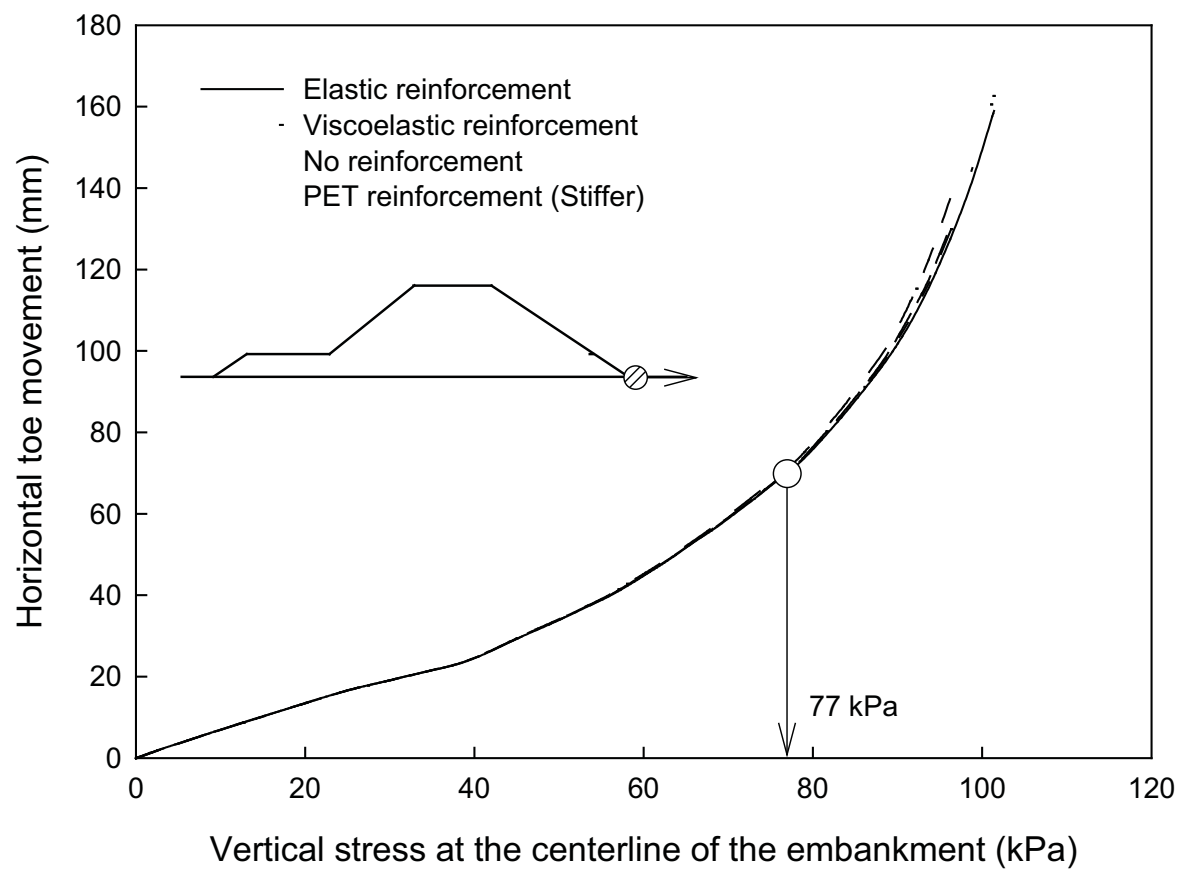

Figure 11. Calculated horizontal toe movement 


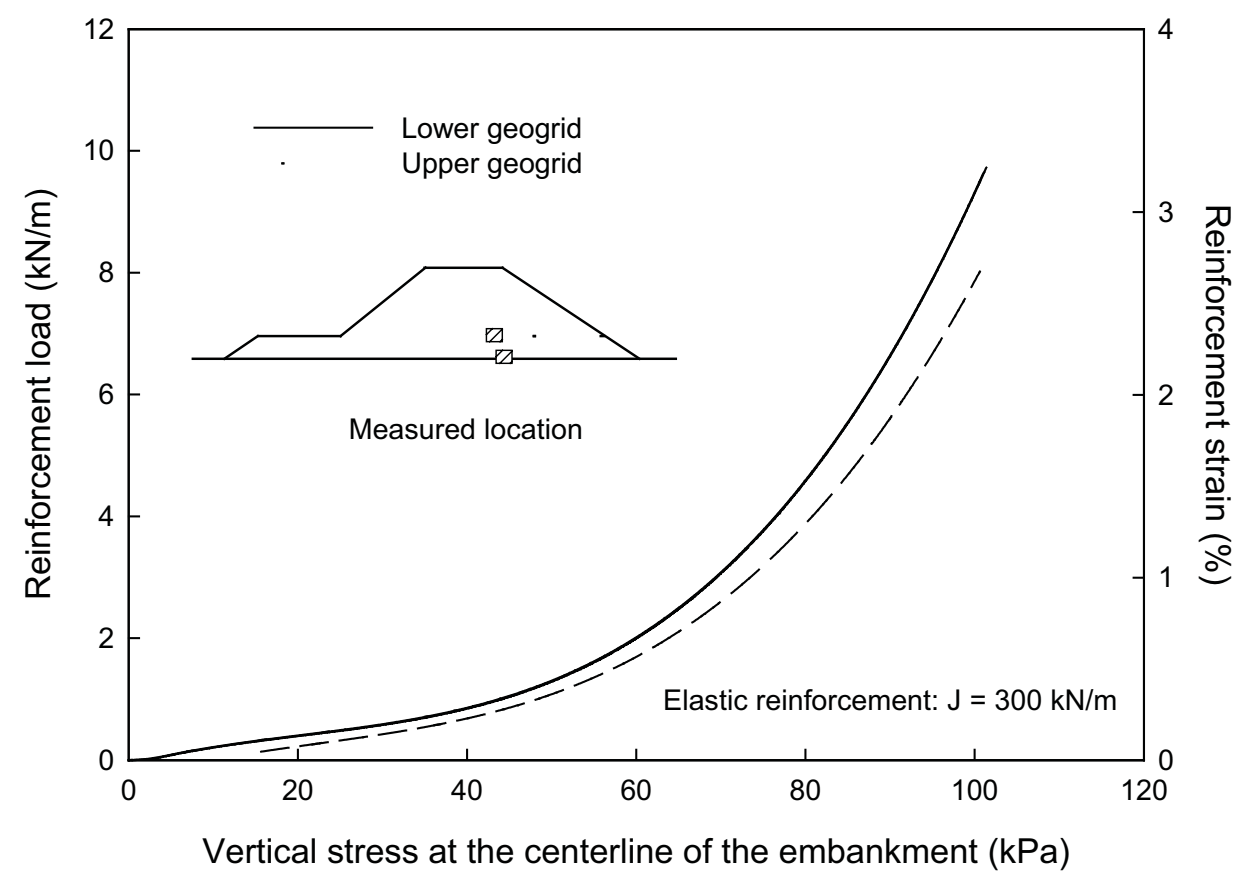

Figure 12. Calculated reinforcement load under embankment crest versus applied pressure at embankment centerline 